\title{
Identification of D-Alanine as the Auto-Inhibitor of Germination of Bacillus globigii Spores
}

\author{
By G. FEY*, G. W. GOULD AND A. D. HITCHINS \\ Unilever Research Laboratory, Colworth House, Sharnbrook, Bedford
}

(Received 1 November 1963)

\begin{abstract}
SUMMARY
Thick suspensions of spores of Bacillus globigii did not germinate completely in nutrient media because the first spores to germinate released a substance which inhibited germination of the remainder. The inhibitory substance was identified as D-alanine by chromatography, high voltage electrophoresis, and its destruction by D-amino acid oxidase. When ${ }^{14} \mathrm{C}-\mathrm{L}$-alanine was used to induce germination of $B$. globigii spores, the resulting inhibitory $\mathrm{D}$-alanine was ${ }^{14} \mathrm{C}$-labelled with the same specific activity as the ${ }^{14} \mathrm{C}-\mathrm{L}$-alanine used. Auto-inhibition of $\boldsymbol{B}$. globigii spore germination is therefore due to racemization of exogenous $\mathrm{L}$-alanine, which forms sufficient $D$-alanine to arrest the germination process in thick suspensions of spores.
\end{abstract}

\section{INTRODUCTION}

More than $99 \%$ of the individuals in suspensions of most types of bacterial spores will germinate in solutions of one or two amino acids or riboside (Hills, 1950); however, germination of suspensions of spores of some organisms may be incomplete in such media and also in complex media (Powell, 1950; Halvorson, 1959). Incomplete germination may have several causes (Murrell, 1961). It has often been noticed that high concentrations of spores germinate less completely than low concentrations. Stedman, Kravitz, Anmuth \& Harding (1956) and Stedman, Kravitz, Harding \& King (1957) found that spores of Bacillus globigii germinating in L-alanine + glucose exhibited pronounced auto-inhibition of germination at high spore concentrations. Their results suggested that, during germination of thick suspensions of $B$. globigii spores, a substance was released into the medium by the first spores to germinate which inhibited germination of the remainder. Stedman et al. (1956) showed that the inhibitor was competitive with L-alanine and suggested that it might be a high molecular weight substance, possibly with a terminal serine residue (Stedman et al. 1957). The strain of B. globigii in our possession also showed auto-inhibition of spore germination, and, since naturally occurring inhibitors of germination are rare, we re-examined the phenomenon to try and identify the auto-inhibitor. When this was proved to be $\mathrm{D}$-alanine, its origin in the supernatant fluid of germinating spore suspensions was investigated.

\footnotetext{
* Present address : Bacteriology Department, Imperial College of Science and Technology, London, S.W. 7 .
} 


\section{METHODS}

Organisms and preparation of spores. Organisms used included Bacillus subtilis v. niger (syn. B. globigii), B. subtilis v. aterrimus мстс 2590, B. subtilis strains м 2 and $\mathrm{s} 5, B$. cereus NCTC 945 and $B$. cereus strains $\mathrm{s} 20$ and PX. The strain of $B$. globigii was obtained from W. Bale (Microbiological Research Establishment, MRE, Porton, Wiltshire) and B. cereus PX from R. E. Strange (MRE, Porton). The other strains were from the National Type Culture Collection (NCTC), Colindale, London, or were laboratory isolates. Spore suspensions were prepared, cleaned and stored as described by Hitchins, Gould \& Hurst (1963), and the dry weights of suspensions were determined by drying samples to constant weight at $105^{\circ}$.

Media and measurement of germination. All spore suspensions except those of Bacillus globigii were heated at $70^{\circ}$ for $30 \mathrm{~min}$. before use. $B$. globigii spores germinated less rapidly after heating and were therefore used unheated at equiv. $75 \mu \mathrm{g}$. dry weight spores/ml. Germination medium for $\boldsymbol{B}$. globigii spores consisted of L-alanine (10 mM), glucose (mM), sodium phosphate buffer ( $\mathrm{pH} 7,30 \mathrm{~mm}$ ). Germination medium for the other spores was composed of L-alanine (500 $\mu \mathrm{M})$, L-tyrosine $(500 \mu \mathrm{M})$, inosine $(20 \mu \mathrm{M})$, glucose $(500 \mu \mathrm{M})$, sodium phosphate buffer (pH 7, $30 \mathrm{~mm}$ ). Germination was measured by examining suspensions with the phase-contrast microscope and recording the \% of phase-dark (germinated) spores. About 250 spores were counted for each estimation. Alternatively, the extinction of suspensions was measured with an absorptiometer ('Biochem', Hilger and Watts Ltd., Camden Road, London) and $560 \mathrm{~m} \mu$ peak transmission filter. Germination was accompanied by a decrease in the extinction of suspensions.

Preparation of the auto-inhibitor. Spores of Bacillus globigii were suspended in germination medium at high concentrations (equiv. $1 \cdot 1 \mathrm{mg}$. dry wt. spores $/ \mathrm{ml}$.). After $1 \mathrm{hr}$ at $30^{\circ}$ only about $20 \%$ of the spores had germinated, indicating that auto-inhibition had occurred (Fig. 1). The spores were removed by centrifugation and the supernatant fluid concentrated tenfold in a rotary evaporator at $40^{\circ}$. Auto-inhibitor in the concentrate was partially purified by one-dimensional chromatography on Whatman No. 3 MM paper with butanol + acetic acid + water $(4+1+5$ by vol.) as solvent (Davis \& Freer, 1960). Thin strips of the chromatograms were cut off and sprayed to locate ninhydrin-positive material, then the remainder of each chromatogram was cut into 1 in. squares which were soaked in water for $1 \mathrm{hr}$ at $4^{\circ}$ with stirring. Eluted material in the water was finally concentrated in the rotary evaporator to the volume of the initial concentrate. Pyridine + ethanol + water $(10+7+3$, by vol. $)$ was also used as a solvent for chromatography. A Locarte instrument (Locarte Co., 24 Emperor's Gate, London, S.W. 7) was used for high voltage paper electrophoresis on Whatman $3 \mathrm{MM}$ paper and with solvent consisting of $\mathrm{M}$-formic acid + acetic acid buffer ( $\mathrm{pH} \mathbf{1 \cdot 8 5}$ ).

Biological assay of the auto-inhibitor. Solutions containing auto-inhibitor were assayed by mixing with fresh germination medium at $30^{\circ}$ containing equiv. about $60 \mu \mathrm{g}$. dry weight Bacillus globigii spores/ml. and the rates of germination were measured by the extinction change and phase-contrast methods. In the absence of auto-inhibitor this low concentration of spores germinated almost completely (Fig. 1).

Use of D-amino acid oxidase. Action of the D-amino acid oxidase from hog kidney (L. Light and Co. Ltd., Colnbrook) was measured by following oxygen uptake in a 
Warburg apparatus at $35^{\circ}$. Incubation mixtures in the flasks consisted of D-amino acid oxidase (16 mg.), sodium pyrophosphate buffer (pH 8.3, $20 \mu$ mole) and either DL-alanine (150 $\mu \mathrm{mole})$, L-alanine (150 $\mu \mathrm{mole})$ or auto-inhibitor solution (1 $\mathrm{ml}$. concentrate) in a total of $2.5 \mathrm{ml}$. (Yoshimoto, 1958). Under these conditions $80 \%$ of the D-alanine was oxidized to pyruvic acid in $5 \mathbf{h r}$.

Estimation of pyruvic acid. Pyruvic acid formed by the action of D-amino acid oxidase on D-alanine was estimated by reaction with 2,4-dinitrophenylhydrazine (Hopkin and Williams Ltd., Chadwell Heath, Essex) after removing the enzyme by precipitation with trichloroacetic acid (Koepsell \& Sharp, 1952). The derivative was extracted into ethyl acetate, and from this into sodium carbonate solution (M). After development with sodium hydroxide (final concentration, $0.4 \mathrm{M}$ ) for $10 \mathrm{~min}$. the intensity of the colour was compared with standards and blanks at $435 \mathrm{~m} \mu$ in a Unicam SP 500 (Unicam Instruments Ltd., Cambridge).

Isotope studies. L-Alanine uniformly labelled with ${ }^{14} \mathrm{C}$ (Radiochemical Centre, Amersham, Buckinghamshire) was diluted with unlabelled $\mathbf{L}$-alanine and used as a germinant for Bacillus globigii spores. Radioactivity of the ${ }^{14} \mathrm{C}$-L-alanine, the ${ }^{14} \mathrm{C}$-D-alanine produced during germination, and the ${ }^{14} \mathrm{C}$ pyruvic acid produced by action of D-amino acid oxidase was estimated with an Ekco Type $\mathbf{N} 664$ B Universal scintillation counter connected to a $\mathbf{N} 530$ automatic scaler using NE 220 scintillation fluid (Nuclear Enterprises (G.B.) Ltd., Bankhead Medway, Sighthill, Edinburgh 11). Adequate controls for quenching were always included and the counts of samples were corrected accordingly. Samples were normally diluted to give about 10,000 counts/ min., which was the optimal counting rate for the equipment used. The specific activity $(\mu \mathrm{c} / \mu \mathrm{mole})$ of the pyruvic acid (and hence of the D-alanine) was calculated from the colorimetric and radioactivity assays and compared with the specific activity of the L-alanine used as germinant. It was reasoned that the specific activity of the pyruvic acid (and therefore of the D-alanine) would be identical with that of the $\mathrm{L}$-alanine if the $\mathrm{D}$-alanine arose solely by racemization.

\section{RESULTS}

\section{Auto-inhibition of germination}

Figure 1 illustrates the effect of spore concentration on the germination of Bacillus globigii spores. It is clear that high concentrations of spores germinated less completely than low concentrations. The supernatant fluids of auto-inhibited cultures inhibited germination of fresh $B$. globigii spore suspensions in L-alanine+ glucose medium or in yeast glucose broth, confirming the work of Stedman et al. (1956). Culture supernatant fluids and partially purified auto-inhibitor solution retained inhibitory activity after evaporation to dryness in vacuo at $40^{\circ}$ and after storage for at least two months at $4^{\circ}$. The auto-inhibitor was not extracted by ether or chloroform. The auto-inhibitor migrated at the same rate as alanine on chromatograms run in two different solvents and during high voltage electrophoresis on paper. It diffused through Visking dialysis membrane and when the diffusate was autoclaved $\left(126^{\circ}\right.$ for $20 \mathrm{~min}$.) some inhibitory activity was lost, as found by Stedman et al. (1956). However, auto-inhibitor eluted from the alanine band on chromatograms was more heat stable than the auto-inhibitor in the crude supernatant fluid. This suggested that the apparent heat sensitivity of auto-inhibitor in crude super- 
natant fluids was due to its reaction with a medium component which was presumably separated from the auto-inhibitor by chromatography. Eluates from the remainder of chromatograms contained no detectable inhibitor of germination. The partially purified auto-inhibitor also depressed the rate of spore germination of 4 out of 6 other Bacillus species studied (Table 1). All these results indicated that the auto-inhibitor was D-alanine.

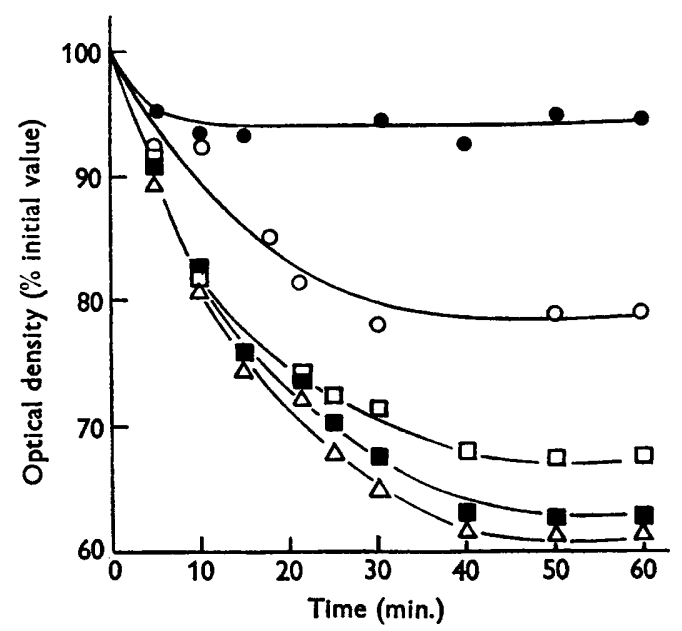

Fig. 1. Effect of spore concentration on the germination of Bacillus globigii spores. Incubation was at $30^{\circ}$ in the defined medium and initial spore concentrations (equiv. mg. dry wt./ml.) were : $0,1.1 ; 0,0.4 ; \square, 0.12 ; \square, 0.06 ; \Delta, 0.05$.

Table 1. Effect of Bacillus globigii auto-inhibitor on the germination of $B$. subtilis and $B$. cereus spores

Purified auto-inhibitor preparation was used at $1 \mathrm{ml} . / 5 \mathrm{ml}$. of suspension.

Decrease in extinction (\%) after $30 \mathrm{~min}$.

$\overbrace{\begin{array}{c}\text { No } \\ \text { auto-inhibitor } \\ \text { added }\end{array}}^{\begin{array}{c}\text { Auto-inhibitor } \\ \text { added }\end{array}}$

B. subtilis NCTC 2590

$\begin{array}{lr}44 & 24 \\ 29 & 1 \\ 20 & 3 \\ 35 & 8 \\ 45 & 42 \\ 65 & 60\end{array}$

Identification of the auto-inhibitor as D-alanine

When a concentrated spore suspension was germinated in medium containing D-amino acid oxidase (1.6 mg./ml.), auto-inhibition was decreased. When autoinhibitor eluted from the alanine band of chromatograms was incubated with D-amino acid oxidase, oxygen was absorbed and, at the same time, loss of inhibitory activity occurred (Tables 2, 3). The keto acid formed was identified as pyruvic acid by the 2,4-dinitrophenylhydrazine method. This confirmed that the auto-inhibitor was D-alanine. 
Table 2. Effect of D-amino acid oxidase on auto-inhibitor and alanine

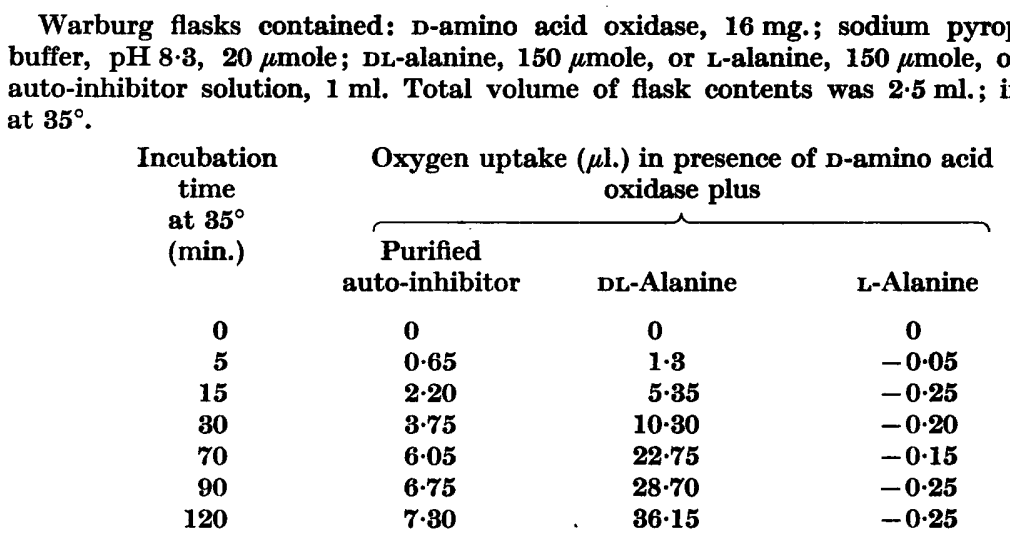

Table 3. Effect of D-amino acid oxidase on the activity of the purified auto-inhibitor

Purified auto-inhibitor was treated with D-amino acid oxidase for $2 \mathrm{hr}$ as described in Methods.

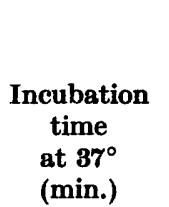

0
15
Germination (\%) of Bacillus globigii spores in yeast glucose broth +

$\overbrace{\begin{array}{c}\text { Untreated } \\ \text { auto-inhibitor }\end{array}}^{\begin{array}{c}\text { D-Amino acid } \\ \text { oxidase-treated }\end{array}} \begin{gathered}\text { No } \\ \text { auto-inhibitor auto-inhibitor }\end{gathered}$

$\mathbf{4}$

16

$\begin{array}{rr}4 & 4 \\ 52 & 88\end{array}$

\section{Origin of D-alanine in supernatants of germinating Bacillus globigii spores}

Three possibilities existed for the origin of the D-alanine: (1) that the D-alanine arose by racemization of exogenous L-alanine; (2) that the $D$-alanine was liberated from endogenous spore material; (3) a combination of (1) and (2). To resolve these possibilities uniformly labelled ${ }^{14} \mathrm{C}-\mathrm{L}$-alanine was used as the germinant. If possibility (1) were correct, the resulting $\mathrm{D}$-alanine should have been ${ }^{14} \mathrm{C}$-labelled with the same specific activity as the ${ }^{14} \mathrm{C}$-L-alanine used as germinant. If possibility (2) were correct, the D-alanine arising from unlabelled spore material should have been unlabelled. If possibility (3) were correct the $D$-alanine should have been ${ }^{14} \mathrm{C}$-labelled but with a lower specific activity than the ${ }^{14} \mathrm{C}$-L-alanine.

During purification of the auto-inhibitor strips of the chromatograms were scanned with a scintillation counter and only the alanine band was radioactive. The auto-inhibitory $\mathrm{D}$-alanine and residual ${ }^{14} \mathrm{C}$-L-alanine in supernatant fluids were eluted from the chromatograms. The D-alanine was estimated by measuring oxygen uptake in the presence of $\mathrm{D}$-amino acid oxidase and also by estimating the resulting pyruvic acid by the 2,4-dinitrophenylhydrazine method. Since the hydrazine method effectively separated the pyruvic acid from any residual ${ }^{14} \mathrm{C}-\mathrm{L}$-alanine, the radioactivity of the pyruvic acid (and hence of the D-alanine) could be determined. Figure 2 illustrates the experimental steps and Table 4 summarizes the results. 
Fig. 2. Scheme for estimation of D-alanine by conversion to pyruvic acid

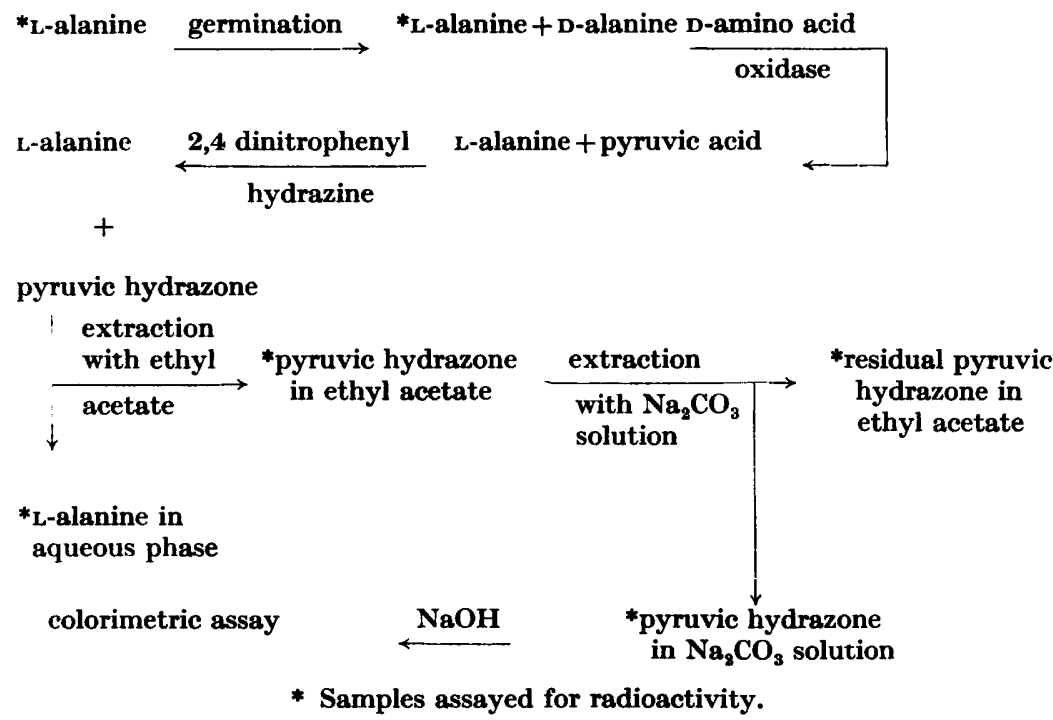

Table 4. Conversion of ${ }^{14} C$-L-alanine into ${ }^{14} C$-D-alanine during germination of Bacillus globigii spores

See Methods for experimental procedure.

\begin{tabular}{|c|c|c|}
\hline & \multicolumn{2}{|c|}{$\begin{array}{l}\text { Amount ( } \mu \text { mole) }),{ }^{14} \mathrm{C} \text { activity }(\mu \mathrm{c}) \\
\text { and specific activity }(\mu \mathrm{c} / \mu \text { mole })\end{array}$} \\
\hline & $\begin{array}{c}\text { Before } \\
\text { germination }\end{array}$ & $\begin{array}{l}1 \mathrm{hr} \text { after start } \\
\text { of germination }\end{array}$ \\
\hline \multicolumn{3}{|l|}{ L-Alanine } \\
\hline$\mu$ mole & 200 & $140 *$ \\
\hline$\mu \mathbf{c}$ & 20 & 13.95 \\
\hline$\mu \mathrm{c} / \mu \mathrm{mole}$ & $0 \cdot 10$ & $0 \cdot 10^{*}$ \\
\hline \multicolumn{3}{|l|}{ D-Alanine (measured as pyruvate) } \\
\hline$\mu \mathrm{mole}$ & $\mathbf{0}$ & $39 \cdot 8$ \\
\hline$\mu \mathrm{c}$ & $\mathbf{0}$ & $5 \cdot 17$ \\
\hline$\mu \mathrm{c} / \mu \mathrm{mole}$ & $\mathbf{0}$ & $0 \cdot 13$ \\
\hline \multicolumn{3}{|l|}{$\begin{array}{l}\text { D-Alanine (measured by } \mathrm{O}_{2} \text { uptake } \\
\text { during enzymic oxidation) }\end{array}$} \\
\hline$\mu$ mole & $\mathbf{0}$ & $\mathbf{3 7 \cdot 0}$ \\
\hline Recovery of ${ }^{14} \mathrm{C}$ label (\%) & 100 & 96 \\
\hline Recovery of L- + D-alanine (\%) & 100 & 90 \\
\hline
\end{tabular}

* Specific activity of L-alanine after germination was assumed to be $0 \cdot 1$ and the $\mu$ mole of L-alanine calculated on this assumption.

It is clear that $96 \%$ of the ${ }^{14} \mathrm{C}-\mathrm{L}-$ alanine supplied as germinant was accounted for after germination as unused ${ }^{14} \mathrm{C}$-L-alanine $+{ }^{14} \mathrm{C}$-D-alanine. Furthermore, the specific activity of the ${ }^{14} \mathrm{C}$-D-alanine (estimated as ${ }^{14} \mathrm{C}$-pyruvic acid) was $130 \%$ of the specific activity of the ${ }^{14} \mathrm{C}-\mathrm{L}$-alanine originally present. This showed that the $\mathrm{D}$-alanine produced by germinating Bacillus globigii spores arose predominantly from the L-alanine used as germinant and not from endogenous spore material. 
A mixture of $8 \mathrm{mM}-\mathrm{L}$-alanine $+2 \mathrm{mM}-\mathrm{D}$-alanine, the concentrations found in auto-inhibited cultures, prevented germination (Table 5).

Table 5. Germination of spores of Bacillus globigii in mixtures of L-alanine and D-alanine

Fresh spores of $B$. globigii were incubated in D-alanine and $\mathrm{L}$-alanine mixtures at $30^{\circ}$. The mixture of $8 \mathrm{~mm}-\mathrm{L}-\mathrm{alanine}+2 \mathrm{~mm}-\mathrm{D}-\mathrm{alanine}$ is equivalent to that found in autoinhibited cultures.

\begin{tabular}{|c|c|c|c|c|c|}
\hline \multicolumn{2}{|c|}{$\begin{array}{l}\text { Concentration of } \\
\text { mixtures (mM) }\end{array}$} & \multicolumn{4}{|c|}{ Extinction (\%) after incubation for } \\
\hline L-Alanine & D-Alanine & $0 \mathrm{~min}$. & $15 \mathrm{~min}$. & $30 \mathrm{~min}$. & 60 min. \\
\hline 10 & $\mathbf{0}$ & 100 & 77 & $72 \cdot 8$ & 70 \\
\hline 8 & 2 & 100 & 93.5 & 98.5 & $92 \cdot 5$ \\
\hline 6 & 4 & 100 & 96.5 & 96.5 & 96.0 \\
\hline \multicolumn{2}{|c|}{$\begin{array}{l}\text { Purified supernatant } \\
\text { of an auto-inhibited } \\
\text { culture }\end{array}$} & 100 & $93 \cdot 5$ & $90 \cdot 0$ & $89 \cdot 0$ \\
\hline
\end{tabular}

\section{DISCUSSION}

The properties of the auto-inhibitor showed that it was D-alanine. This was confirmed by the labelling experiment, which further showed that the D-alanine originated from the $\mathrm{L}$-alanine supplied as germinant and not from spore constituents, although $D$-alanine is present in spore mucopeptide (Strange \& Thorne, 1957). When D-amino acid oxidase was added to Bacillus globigii spore suspensions at the start of germination, the auto-inhibitory effect was decreased; Stedman et al. (1956) were unable to show this. Such a discrepancy may be due to differences in the strains of $B$. globigii used or to different activities of the oxidase preparations or even to different mechanisms of auto-inhibition.

$\mathrm{I}$-Alanine is a well-known inhibitor of spore germination (Hills, 1949) which probably acts by competing with $\mathrm{L}$-alanine for the active site of $\mathrm{L}$-alanine dehydrogenase (O'Connor \& Halvorson, 1961). Stedman et al. (1956) showed low concentrations of alanine racemase in Bacillus globigii spores but Church, Halvorson \& Halvorson (1954) did not detect it in the spores of this organism. Under the conditions of our experiments, however, the only way $D$-alanine could be formed from L-alanine was by the racemization reaction catalysed by alanine racemase; no attempt was made to extract the enzyme from spores.

One value of racemase in spores has been pointed out by Wolf \& Mahmoud (1957): it enables spores to germinate slowly in D-alanine. In addition, however, it will prevent complete germination of dense populations of spores. Spores will often germinate in environments unsuitable for further growth; incomplete germination can therefore have a survival value because the ungerminated spores will survive and be able to germinate later. Auto-inhibition, the phenomenon in which large fractions of a spore population remain ungerminated, even when germinants are present in excess, has been observed in other Bacillus species (Murrell, 1961). Alanine racemase commonly occurs in spores of the genus Bacillus (Wolf \& Mahmoud, 1957) and Powell (1957) obtained evidence that this enzyme was involved in auto-inhibition of germination of $\boldsymbol{B}$. subtilis spores. In explaining auto-inhibition 
of germination of spores of other species the mechanism described here for $\boldsymbol{B}$. globigii must therefore be considered, particularly when L-alanine is known to be required for germination of the spores. Generally, bacterial spores respond to sublethal heating by germinating more rapidly than when unheated (Curran \& Evans, 1944). Bacillus globigii spores, however, respond to sublethal heating by germinating less rapidly than when unheated. It is not known whether this phenomenon is related to auto-inhibition (for instance, by heat activation of the racemase), but heat-induced dormancy is not restricted to $B$. globigii, for Finley \& Fields (1962) noticed a similar phenomenon with spores of $B$. stearothermophilus.

We are indebted to $\mathrm{Dr}$ A. Hurst for valuable advice and criticism and to $\mathrm{Mr}$ R. V. Harris for help and advice with the radioactive assays.

\section{REFERENCES}

Church, B. D., Halvorson, H. \& Halvorson, H. O. (1954). Studies on spore germination: its independence from alanine racemase activity. J. Bact. 68, 393.

Curran, H. R. \& Evans, F. R. (1944). Heat activation inducing germination in the spores of thermophilic aerobic bacteria. J. Bact. 47, 437.

Davis, G. H. G. \& Freer, J. H. (1960). Studies upon an oral aerobic actinomycete. J. gen. Microbiol. 23, 163.

Finley, N. \& Fields, M. L. (1962). Heat activation and heat-induced dormancy of Bacillus stearothermophilus spores. Appl. Microbiol. 10, 231.

Halvorson, H. O. (1959). Symposium on initiation of bacterial growth. IV. Dormancy, germination and outgrowth. Bact. Rev. 23, 267.

HrLls, G. M. (1949). The effect of amino acids on the germination of Bacillus anthracis with some observations on the relation of optical form to biological activity. Biochem. J. 45, 363.

Hills, G. M. (1950). Chemical factors in the germination of spore bearing aerobes: observations on the influence of species, strain and conditions of growth. J. gen. Microbiol. 4, 38.

Hitchins, A. D., Gould, G. W. \& Hurst, A. (1963). The swelling of bacterial spores during germination and outgrowth. J. gen. Microbiol. 30, 445.

KoEPSELL, H. J. \& Sharp, E. S. (1952). Microdetermination of pyruvic and $\alpha$-ketoglutaric acids. Archs. Biochem. Biophys. 38, 443.

MurrelL, W. G. (1961). Spore formation as a microbial reaction to the environment. In Microbial Reaction to Environment. Symp. Soc. gen. Microbiol. 11, 100.

O'Connor, R. J. \& Halvorson, H. O. (1961). L-Alanine dehydrogenase: a mechanism controlling the specificity of amino acid-induced germination of Bacillus cereus spores. J. Bact. 82, 648.

Powell, J. F. (1950). Factors affecting the germination of thick suspensions of Bacillus subtilis spores in L-alanine solution. J. gen. Microbiol. 4, 330.

Powell, J. F. (1957). Biochemical changes occurring during spore germination in Bacillus species. J. appl. Bact. 20, 349.

Stedman, R. L., Kravitz, E., Anmuth, M. \& Harding, J. (1956). Autoinhibition of bacterial endospore germination. Science, 124, 403.

Stedman, R. L., Kravitz, E., Harding, J. \& King, J. D. (1957). Further studies on bacterial endospore germination relative to autoinhibition. Food Res. 22, 396.

Strange, R. E. \& Thorne, C. B. (1957). D-Glutamic acid and D-alanine as constituents of spores of Bacillus megatherium. Biochim. biophys. Acta, 24, 199.

Wolf, J. \& MAnmoud, S. A. Z. (1957). The effects of L- and D-alanine on the germination of some Bacillus spores. J. appl. Bact. $20,373$.

Yosнiмото, S. (1958). The action of D-amino acid oxidase on $\epsilon$-acyllysine and lysine. Archs. Biochem. Biophys. 75, 280. 